\title{
COMMON ERRORS IN FIRE FIGHTING
}

\author{
By C. F. HOLMES
}

\author{
British Columbia Forest Service, Vancouver, British Columbia \\ Too Little and Too Late
}

$\mathrm{T}$ HIS IS INTERPRETED to mean failure to attack a fire with enough men and equipment at the earliest moment. It embraces those cases where an operator waits for a Forest Officer to issue written instruction. The indicated need is rather to err in the other direction. Use all avail. able force of men and equipment (men in relays) that can be brought to bear on the fire, and then get back to normal occupations as rapidly as complete suppression and extinguishment of the fire warrant.

Lack of Adequate Reconnaissance

Primary examination of all sides of a fire is essential if the fullest advantage is to be taken of existing aids. The man in charge or a reliable deputy should go around the fire and make note of all factors; failure to secure this knowledge has resulted in fires being lost which might have been stopped at game trails, donkey-drags, creeks, etc., had full intelligence of conditions been obtained. Lack of careful inspection at the first opportunity results in evidence as to point of origin and cause of fire being ob. scured, and these may affect litigation, prevent a repetition, or interest a person engaged in research at a later date.

Also, fires which have been brought under control have sneaked or smudged across their boundaries due to carelessness in subsequent reconnaissance. The importance of continuing effective patrol until all sign of fire has ceased is essential if a recurrence is to be prevented.

\section{LaCK of Intensive Supervision on the Fire Line}

Fire fighting is a disorderly activity at its best. The conditions are frequently those of haste, bordering on panic. It requires close supervision if anything resembling economy of time, costs, and values is to be realized.

Where a large logging operation is committed to fighting a fire with all its crew, provision is desirable for enough strawbosses, foremen, and other key men to set up a chain of responsibility so that the will and purpose of the man in charge may be accomplished.

Instead of turning a crew of men loose on a side-hill, improperly tooled, inefficiently led, and indifferently disposed toward the work in hand, small groups of 8 men under a strawboss, who in turn is responsible to a foreman having 4 or 5 such groups in his command, should be set up. The foreman in turn would be instructed by the next senior officer who might be the logging superintendent or the woods foreman. General responsibility for contacts with neighbouring interests, and overall co-ordination with Gov, ernmental authority and resources, are assumed by the local forest officer. It is incumbent on all logging companies to report fires by the quickest means at their disposal to the Forest Service. 
Failure to Relate Work to Meteorological Conditions

Fire behavior varies with changing weather conditions, and attack should vary accordingly, from direct to indirect methods in suppression. Very early in the morning work may be done with advantage right against the edge of the fire. Mid afternoon and evening work may perforce have to be done at some distance back with a view to back-firing fireguard so constructed. To attempt work at the head of a fire, or on the high sides, during the hours of low humidity daily, or during windy weather is poor strategy. It may also be highly dangerous to personnel, and invariably entails loss of tools and equip. ment. An overall rule for the east coast of Vancouver Island is that fires run toward the South-East, and that the majority of escapes have been out of the South-East corner of the fire. This applies as far South as Mile 17 on the Malahat; from which point southerly and westerly around the south end of the island to a point 15 miles west of Jordan River fires run most fiercely and challenge most persistently toward the North-East. The exception to the foregoing is where a local wind condition results in a day and night air movement up and down waterway trenches.

Quitting the fire, or reducing crew which could be usefully employed in consolidating gains, when night or kindlier weather slows the fire to a walk or stops it altogether is a common error, and one which has often proved costly.

Failure to Use Fire to the Utmost in Eliminating Further Fuel SOURCe, ThEREBy InVITING ReCURRENCE

There is no fire so satisfactorily tied in and suppressed as one enclosed in a trail to mineral soil and completely burned out.

Fires with gun-shotted heads or messy flanks frequently present unburned islands inside the main fireguard. These unburned areas should be isolated by encircling fireguards, or if it is the intent to burn them this should be done at the earliest opportunity. The only useful purpose served by a main fireguard, if a fire has temporarily petered out within a chain or two of it, is improved access; but insofar as stopping the fire, or subsequently holding it within bounds goes, a mark smeared across the landscape with a whitewash brush would serve almost as well.

The Misuse of Water

If water is used wisely and in sufficient quantity there is no better means of extinguishing certain types of fires; as for instance those in felled and bucked timber.

The misuse of water has been responsible for fires being retarded only to recur. It has resulted in essential fireguard not being contsructed, backfires not being cleanly burnt out, and a false sense of security taking hold of the fire fighters.

From the B.C. Forest Service record-"This fire was controlled to 120 acres by the operator who used 2 R.D.'s and followed up with tank cars. Guard did not competely enclose fire there being approximately 20.00 chains open at S.E. corner. Operator protested later that he was unable to put a fire-trail there because there was too much rock for the cats, and so he decided to fight that part of the line with pumps. 
The operation had shovels, mattocks, and usual run of hand-tools to equip 300 men, but lacked a well-led crew of 20 men necessary in this instance to put in a hand trail.

Fire subsequently took in 27 more forties, and disrupted all log produc. tion for 12 days."

The tactical error of wetting down on the wrong side of the fireguard results in lessened opportunity to light backfires and too often leaves an un. burned fringe of debris between the fire and the fireguard, which is a continuing threat. The correct thing to do is to wet down on the outside of the trail, backfire the inside, and hot clean-and speedily.

It is conceded that if a main fire is coming too quickly toward a fireguard and water is available at that point, it is good practice to put some water on it to reduce the heat, but only just enough to retard it to controllable dimensions.

\section{Making Wrong Sort of. Fireguard}

The prime reason for a fireguard is to establish a point from which to set a backfire. All fireguards have length, depth, and width. They should be as short as possible to completely enclose (in conjunction with existing aids such as roads, trails, watercourses, etc.) the fire. They should cut completely through debris; duff, and humus to rock or mineral soil if at all possible. Acceptable width varies from 16-inch which may well constitute hand-made guard affording full scope as a place from which to set out a successful backfire, to 16 feet which may be convenient width for a bulldozer job over which a tank truck is to be used.

Fireguards sited through shaded bottom land carrying deciduous cover bave access value only. There is a tendency for fire-fighters to congregate and waste time in such places rather than to get out in the heat of the sun and work where trail is urgently needed to stop a fire. This is indicative of the need for closer supervision and smaller working units under competent strawbosses.

Siting the fireguard, so that it may fulfil all requirements with a minimum of labor and cost, is of first rate importance, and a really first class man should be detailed for this work. He will avoid snags which otherwise must be felled, avoid heavy ground debris, choose most favourable topographical elevations, and come in or go back from the fire as opportunity to complete work presents itself.

Western Fire Fighters' Manual, Chapter VII, 1934, Osborne, W. B., has an excellent passage on "Snags" on pages 83-85, and also lists as one of the "Common errors in fire fighting" page 111, 8. "Failure to throw dangerous snags." In this connection it is noted that snag-felling is mandatory by statute in British Columbia, and has been since the passage of Section $113 \mathrm{~A}$ of the Forest Act in 1938. This has resulted in the disappearance of this phase of the hazard on areas logged during the last decade, although there are still lands which were logged previous to 1938 not snagged, and to which these remarks apply. 
Other errors in fireguard construction include chopping brush or hacking ground vegetation and leaving it too close to the trail. Through reproduction chopping should be 8 feet wide, and debris so cut may be disposed of by throwing it to either side of the freguard provided it is thrown far enough.

Exception is also taken to the practice of shovelmen digging holes in the middle of the trail, and leaving them. If a few shovels of mineral soil are needed in a hurry to throw on a spot fire across the guard, or other immediate need, the fire-fighter is justified in getting it wherever he can do so most easily, and this may mean the centre of the trail; however, there may be a night patrol or somebody may pass there on the run at a time when smoke obscures the footing. A good strawboss will not leave man-traps of this sort.

\section{Failure to Backfire EFFectively}

As backfiring is usually an essential factor in fire suppression the only question remaining is one of terms and conditions. Ideal conditions sometimes prevail, such as night, still air or a favourable wind, a definite break in fuel type as the edge of a slash, a first class fireguard with all snags down, abundant water and necessary equipment to deliver it where needed, enough men under intelligent leadership to do the work, even perhaps a spot or two of rain, but this not the general rule. Not only may these aids be lacking, but grievously adverse conditions in whole or in part may prevail. The attempt to backfire should be made on the best terms that can be devised, whenever the main fire forces the issue. Viewed as a gamble the effort is worthwhile, because if a backfire gets out of hand it is proof positive that the main fire would have roared by on the run had no backfire been used. Osborne WFF Manual Chap. 7, page 111, under "Common errors in fire fighting" " 6 ", lists "construction of a fire line in advance of a fire with no attempt to backfire. A costly monument to misjudgment or inefficiency." Failures to backfire effectively heretofore have stemmed from inferior leadership and recklessness by people of immature or inexperienced degree. Too much should not be lighted up at one time. Other mistakes are failure to wet down the fireguard and the outside of that guard; failure to have snags felled; failure to have ground debris removed adjacent to fireguard; and failure to have spotters out at some distance back from the fireguard. These latter could well be men with buckets, hand-tank pumps, shovels, operating from stumps or from wherever they can see most territory. Spot fires should be jumped on immediately. Also, a common failure is neglecting to mesh with the next process on the fire which is "mop up and patrol".

\section{Reducing Crew or Quitting FiRe TOO SOON}

It is false economy and foolhardiness in the extreme to treat a fire that has brought under control with disrespect.

Once an initial decision has been obtained efforts should be made to consolidate the line. Bulldozers are valuable aids in breaking out landings, scattering sawdust or mill waste piles, and widening or deepening dangerous places. Pumps and water tanks may well be employed lavishly now that everything that will readily burn has been burned. Spot fires should be checked and re-checked. The aim should be to get in the knockout punch 
rather than allowing the adversary to recuperate. An alert patrol should be kept on the fire for several days after all vestige of smoke has been dispelled, after which weather conditions should be carefully noticed and due inspections made to see that there is no recurrence. It is noted that authority in writing from the Forest Service (Section 118 of the Forest Act) is required to reduce crew once they have been called out to fight fire on a logging operation.

\section{Improper Use Of, and Failure to Gather Up and Refit, TOOLS AND EQUIPMENT}

The sum total of monies spent by logging companies annually in purchase of fire fighting tools and equipment is immense. It is not equally clear that employees make the best use of those tools or that they give them proper care. Excessive damage is sustained by hose, due to people walking on it while wearing caulked boots.

Too frequently hose is left uncared for after a fire instead of being washed, dried, repaired, and rolled up without delay.

The toll is heavy in burned, broken, abandoned, or stolen hand tools. (Loss by theft might be obviated by branding all tools.)

Tools in waiting are left out in the sun or taken away for purposes other than fire fighting, and not returned.

To prevent the foregoing better supervision is required. The aim should be to have all tools gathered up after a fire, put in serviceable condition, and returned to storage.

Unpreparedness and An Absence of Goodwill

In the B.C. Forest Service there is at each ranger station a pre-organization chart, with copy filed at the District Office.

Logging operators might well adopt this idea, and with the necessary changes from the Department's pattern, set up their own plan for fire prevention on their operations.

This requires a map of the company holdings; a map or sketch showing fuel hazards; and a fire-prevention facilities (overlap) map to include roads, trails, lookouts, phones, etc. There should also be a list of phone numbers of key employees, forest officers, and neighbouring interests. It should itemise tools and equipment, where stored and quantity, as in main and decentralized caches. It is understood, of course, that many of the larger operations have a fire-warden and it is assumed that he knows where the equipment is, but it is always possible that the fire-warden might be a casualty.

Attention might be given to training and instructing employees. Sug. gestions might be invited. Some companies have cash incentives now for prevention of accidents. Also prizes might be offered for sound ideas from employees. Pre-season talks to keymen, picture shows, and a careful screening of personnel to eliminate the disaffected are other preventive measures. 
Pre-organization will dispel the present apathetic state of unpreparedness (a common and costly error) which is of fairly general occurrence among loggers. It should instil in its place an awareness of fire-danger to livelihood and investment alike, coupled with confidence to meet it with less disadvantage than heretofore.

In all things done and said the factor of goodwill should be borne in mind. There is no substitute for this at any time, but it becomes doubly valuable when adversity smites in the form of fire. A really live personnel officer with the gift of persuasion and the power to teach is an invaluable asset in forest fire preventive and fighting techniques. 